\title{
Theoretical and methodological grounds for critical approach to revolution
}

\section{S. A. Kudrina ${ }^{1}$}

1P. G. Demidov Yaroslavl State University, 14 Sovetskaya str., Yaroslavl 150003, Russian Federation

DOI: $10.18255 / 2412-6519-2020-1-46-53$

Research Article

Full text in Russian

The article is devoted to the sociological approach to the phenomenon of revolution as a "pure type" free from political and historical content. It deals with socio-ontological, methodological, socio-psychological and ethical-axiological grounds for the critical approach to the phenomenon of revolution in classical and contemporary theories. Socio-ontological arguments are proposed by sociologists who regard revolutions as disaster because social systems (as "living organisms" or any complex systems, regardless of their origin) are certain to be in balance. According to the socio-psychological critical arguments, revolutions activate irrational aggressive crowds capable of destruction only. Besides, this approach is based on the study of false interpretations and the phenomenon of the "revolution of rising expectations". Methodological criticism aims at social revolution as an inevitable integral element of Utopian engineering. The meaning of the confrontation is as follows: piecemeal technology versus holistic largescale experiment. According to the ethical and axiological arguments, the revolution as a violent collective action, in the name of the desired equality and justice, leads to victims inevitably.

Keywords: sociology of revolution; social change; holism; social exclusion; justice; revolution of rising expectations

INFORMATION ABOUT THE AUTHORS

$$
\begin{array}{l|l}
\text { Kudrina Sofia A. } & \begin{array}{l}
\text { E-mail: sofia-kudrina@mail.ru } \\
\text { Candidate of Sciences in Philosophy }
\end{array}
\end{array}
$$

For citation: Kudrina S. A. Theoretical and methodological grounds for critical approach to revolution // Social'nye i gumanitarnye znanija. 2020. Vol. 6, No 1. P. 46-53. (in Russ.) 


\title{
Теоретико-методологические основания критического подхода к революции
}

\author{
С. А. Кудрина ${ }^{1}$
}

1Ярославский государственный университет им. П. Г. Демидова, ул. Советская, 14, Ярославль, 150003, Российская Федерация

DOI: $10.18255 / 2412-6519-2020-1-46-53$

удК 316.2
Научная статья

Полный текст на русском языке

Статья посвящена социологическому осмыслению феномена революции как «чистого типа» при максимально возможном отвлечении от политических и конкретно-исторических исследований. Рассмотрены социально-онтологические, методологические, социально-психологические и этико-аксиологические основания критического подхода креволюции, предлагаемые как представителями классической социологической мысли, так и современными социологами. Социально-онтологические доводы приводят социологи, в чьих концепциях в той или иной степени делается упор на деструктивности революции и важности сохранения целостности, баланса и равновесности общества, представляющего собой живой организм, подобие живого организма или какую-либо иную сложную систему вне зависимости от того, какова природа этой системы. Социально-психологические основания критического подхода к революции опираются на выводы о разрушительности, агрессивности и иррациональности порождаемых революцией толп, а также на исследования проблемы ложных интерпретаций и феномена «революции растущих ожиданий». При рассмотрении методологических оснований обращается внимание на противопоставление «постепенной технологии» холистскому крупномасштабному эксперименту и на революцию как первый этап утопического проекта. Социологи, выдвигающие этико-аксиологические аргументы, обращают внимание на то, что революция как насильственное коллективное действие во имя желаемого равенства и справедливости неизбежно ведет к жертвам.

Ключевые слова: социология революции; социальные изменения; холизм; социальная эксклюзия; справедливость; революция растущих ожиданий

ИНФОРМАЦИЯ ОБ АВТОРАХ

Кудрина София Альбертовна $\quad$ E-mail: sofia-kudrina@mail.ru

Кандидат философских наук, доцент кафедры философии

Для цитирования: Кудрина С. А. Теоретико-методологические основания критического подхода к революции // Социальные и гуманитарные знания. 2020. Том 6, № 1. С. 46-53.

(C) Кудрина С. А., 2020

Статья открытого доступа под лицензией СC BY-NC-ND (http://creativecommons.org/licenses/by-nc-nd/4.0/) 
Феномен революций, изучаемый с конкретно-исторических, экономических, политико-технологических и философских позиций, представляет большой интерес в том числе и для теоретической социологии. В данной статье будет рассмотрен ряд теоретико-методологических оснований критического подхода к революции в социологии.

В первую очередь следует обратить внимание на социально-онтологические основания критического подхода к рассматриваемому явлению. Сам по себе критический взгляд на революцию начал формироваться в Европе вместе с институционализацией социологии как науки. Первыми, кто поднял данный вопрос, были представители биологического редукционизма. Вообще биологический редукционизм (и возникший вместе с ним структурный функционализм) во многом способствовал развитию критического отношения к революциям в целом, поскольку предполагал рассмотрение общества как единого организма или его подобия, развивающегося непременно эволюционным путем, или путем наименьшего сопротивления. Герберт Спенсер, сторонник и теоретик органической концепции общества, а также его многочисленные последователи расценивали революции как катастрофы и нарушение равновесия, которые тем не менее при несоответствии между чувствами и волей народа и политикой власти оказываются неизбежными. Спенсер обращает внимание на тот парадокс, что «насильственные перевороты, низвергающие старый порядок, не осуществляют надежд тех, кем они производятся, и в окончательном результате порождают учреждения, превосходящие лишь немногим только что уничтоженные», но при указанном выше несоответствии «произведенные изменения не могли произойти никаким иным путем» [1, с. 428].

Социология революции развивалась не только по своей внутренней логике. У человечества накапливался опыт революций. Каждое последующее поколение мыслителей имело возможность обращаться все к более богатому опыту и все более разнообразному эмпирическому материалу. К примеру, автор «Левиафана» Т. Гоббс, который рассматривал революцию и следующую за ней гражданскую войну как «войну всех против всех», еще не знал революций более поздних, чем английская буржуазная, а работа П. Сорокина «Социология революции» была написана уже после русской революции 1917 года, но он еще не мог учитывать такие явления, как, к примеру, «арабская весна». Социологи зачастую углубляются в исторические факты, анализируют конкретную революцию - ту, что близка им по времени, или ту, свидетелями которой они стали лично.

Наша задача - рассмотреть чисто социологические общие выводы о революции как «чистом типе» (термин М. Вебера), абстрагируясь от политических и конкретноисторических рассуждений. К тому же, социально-онтологический подход как раз и дает такую возможность. Еще один пример такого подхода - социология революции Питирима Сорокина. Несмотря на то, что П. Сорокин был очевидцем именно русских революций 1905 и 1917 годов, тем не менее он задался целью не просто осмыслить их, но и исследовать революцию вообще как социологический феномен. Свои выводы он изложил в работе «Социология революции». В качестве причин революций он выделял подавление базовых инстинктов, дезорганизацию власти и социального контроля, когда «на вершине общества аккумулируются «бездарные правители», а «головастиков» у основания пирамиды власти становится все больше и больше» [2, с. 292]. При этом бездарная элита усиливает давление, чтобы сохранить 
власть и привилегии, что чревато взрывом снизу. Этот взрыв происходит, элита сбрасывается вниз, низы поднимаются - то есть рушится стратификация и система социальных «сит». Затем создаются новые «сита», новые механизмы репрессии и подавления. Они и становятся причиной второй неизбежной стадии революции контрреволюции, поскольку накапливаются новые «репрессии», «паразитизм» и «разложение» [Там же].

Социально-онтологическое основание критического подхода к революции можно обнаружить в позиции представителей структурного функционализма, зародившегося на ранних этапах развития социологии и получившего свое продолжение в работах социологов XX в. Считая необходимым сохранение баланса между социальными институтами, функционализм предполагает гибкое приспособление к изменениям и реорганизацию институтов. «Функционализм рассматривает порядок и баланс сил в качестве нормального состояния общества» [3, с. 30]. К социальноонтологическим можно отнести также религиозные концепции общества, которые усматривают в революции нарушение онтологической вертикали. В целом социально-онтологические доводы приводят холисты, в чьих концепциях в той или иной степени делается упор на сохранение целостности, баланса и равновесности общества, которое представляет собой живой организм, подобие живого организма или какую-либо иную сложную систему вне зависимости от того, какова природа этой системы.

Социально-психологические основания критического подхода к революции также имели весьма большое значение для изучения данного феномена. Они были связаны в основном с анализом такого явления, как толпа. По мнению Гюстава Лебона, революция порождает толпы, и какими бы высокими ни были идеалы революции, разумности в действиях толпы никогда не было и быть не могло. «Толпа никогда не стремилась в правде; она отворачивается от очевидности, не нравящейся ей, и предпочитает поклоняться заблуждению, если только заблуждение это прельщает ее. Кто умеет вводить толпу в заблуждение, тот легко становится ее повелителем; кто же стремится образумить ее, тот всегда бывает ее жертвой» [4, с. 148]. При этом, пребывая в иррациональном состоянии и совершая преступление, толпа вовсе не способна к раскаянию, в отличие от преступника-одиночки; в толпе человек утрачивает личную ответственность: «Преступления толпы всегда вызваны каким-нибудь очень могущественным внушением, и индивиды, принявшие участие в совершении этого преступления, убеждены, что они исполнили свой долг» [5, с. 222].

Габриэль Тард в своей работе «Общественное мнение и толпа» выделяет следующие черты толпы: «чудовищная нетерпимость, забавная гордость, болезненная восприимчивость, доводящее до безумия чувство безнаказанности, рожденное иллюзией своего всемогущества, и совершенная утрата чувства меры, зависящая от возбуждения, доведенного до крайности взаимным разжиганием» [6, с. 282]. По причине иррациональности «для толпы нет середины между отвращением и обожанием, между ужасом и энтузиазмом, между криками да здравствует! или смерть!.. И достаточно мелочи, чтобы обожествление превратилось в вечное проклятие». Жестокость толпы как явления прошлого возвращает человека к обезличенной агрессивности: «Во все времена и во всех странах убивающая или грабящая толпа считает себя судьей, и тот короткий суд, который она учиняет, странно напоминает по мстительному характеру наказаний, по их неслыханной жестокости... правосудие первобытных времен» [Там же. С.293-294]. Именно поэтому даже самый разумный 
революционный план, каким бы гуманным он ни казался, так или иначе несет в себе не столько возможность созидания, сколько опасность деструктивных действий: «Но можно ли назвать хоть один дом, построенный толпой, землю, распаханную и возделанную толпой, какую-либо промышленность, созданную толпой? За несколько тощих деревьев свободы, которые они посадили, сколько выжженных лесов, разграбленных гостиниц, разрушенных дворцов! За одного популярного узника, которого они иногда освобождали, сколько казней по суду Линча, сколько тюрем, взятых приступом... революционными массами с целью избиения узников ненавистных, возбуждающих зависть или страх!» [Там же. С. 287].

Рассматривая социально-психологические основания критического подхода к революции, следует обратить внимание на то, что важную роль в формировании революционных настроений играют интерпретации, определения ситуаций и ожидания, которые могут оказаться не только иррациональными, но и вообще лишенными каких бы то ни было объективных социально-политических или экономических причин. В своей последней работе «Ретротопия» Зигмунт Бауман писал, что революция вызвана «гневом обездоленных и брошенных», но этот гнев порождает «не абстрактный эталон справедливости», а либо «сравнение себя с окружающими людьми, живущими рядом в «реальном времени»» [7, с. 97], либо «растущие ожидания», когда «вчерашнее продвижение вверх по социальной лестнице, если оно прекратилось и не продолжается сегодня, порождает и усиливает обиду тем, что тебя якобы унизили» [Там же. С. 98]. И здесь депривация не столько объективная, сколько субъективная. Этим объясняется, по Бауману, феномен «революций растущих ожиданий». «Недовольство, приводящее в конце концов к протестам и восстаниям, детерминируется вовсе не какой-то абсолютной, «объективной» мерой количества и тяжести переносимых лишений, а отклонением в количестве и интенсивности от привычного их распределения между различными секторами общества - от соотношения, которое воспринимается как нормальное, а потому - легитимное» [Там же. С. 96]. Кроме того, насилие, которое эти революции сопровождает, «губительно привлекает тем, что дает временное избавление от унизительного чувства собственной неполноценности - слабости, бесталанности, никчемности, ничтожества» [Там же. С. 46], что «позволяет завлекать в сети еще больше новобранцев, жаждущих «большого дела» (которое придало бы смысл - конечно же, благородный - их блеклому, вялому, никчемному существованию)» [Там же. С. 48]. В XXI веке чувство унижения и гнева подкрепляется усугубляющейся социальной эксклюзией, и на этом чувстве играют циничные популисты, для которых «гнев обездоленных и брошенных - необычайно богатая руда» [Там же. С. 73].

Обратимся теперь к методологическим основаниям критического подхода к революции. В этой связи следует вспомнить идеи Карла Раймунда Поппера, автора работ «Нищета историцизма» и «Открытое общество и его враги». Поппер обращал внимание на то, что существует выбор между двумя способами осуществления социальных изменений - постепенной технологией, или методом осторожных «проб и ошибок» (чего он придерживался сам), и историцистским радикальным холизмом, предполагающим революционный переворот с целью полного отказа от существующего порядка и последующего воплощения в жизнь утопического проекта. Идея постепенной социальной инженерии представлялась Попперу более разумной. Она не предполагает построения идеального общества здесь и сейчас; политик, практикующий постепенную технологию, занимается разработкой методов «для поиска 
наиболее тяжелых, нестерпимых социальных бед, чтобы бороться с ними, а не искать величайшее конечное благо, стремясь воплотить его в жизнь» [8, с. 200]. Данный метод, по мнению Поппера и его единомышленников, - единственный способ улучшения положения дел, действительно приводящий к успеху в любое время и в любом месте; и этим он отличается от метода, который «всегда приводил только к подавлению разума насилием и к отказу либо от самого метода, либо от его первоначального замысла» [Там же. С. 201].

Поппер утверждал, что прийти к разумному соглашению относительно способов решения существующих социальных проблем легче, чем определить бесспорное идеальное благо и приемлемые для всех пути его достижения. К тому же проекты, предлагаемые постепенной инженерией, относительно просты и не затрагивают, как правило, всего объема социальных институтов; поэтому, если эти проекты не дают эффекта, то ущерб от них не столь велик, и исправить ошибки не так сложно, как в случае с неудачным холистским планом. Крупномасштабный эксперимент, начинающийся с революционного переворота, диктует утопистам только один способ дальнейшего поведения: оправдываться и доказывать свою правоту. И напротив, попытки экспериментов в случае постепенной технологии могут повторяться множество раз с учетом совершенных ошибок. «Именно так, а не путем утопического планирования или исторических пророчеств сфера политики сможет обогатиться научным методом, так как секрет научного метода состоит всего лишь в готовности учиться на ошибках» [Там же. С. 206].

Далее рассмотрим этико-аксиологические основания критического подхода к революции. В данной статье уже упоминалась концепция социологии революции П. Сорокина. П. Штомпка в своей классификации теорий революции отнес эту концепцию к бихевиористским [9, с. 183], однако основания именно критического подхода к революции, которые Сорокин предлагает в своей работе, касаются как социальноонтологического аспекта явления (о чем уже было сказано выше), так и этико-аксиологического. Выступая против «слащавых» концепций революции, Сорокин пишет, что «все революции и постреволюционные периоды, как правило, не только не давали приращения свободы, но чаще сопровождались ее сокращением», что «каждый революционный период отмечен ростом убийств, садизма, жестокости, зверств и пыток» [2, с. 267] и что «революция есть худший способ улучшения материальных и духовных условий жизни масс» [Там же. С. 270]. Сравнивая революцию с редкой болезнью, Сорокин развеивает романтические иллюзии революционных Дон-Кихотов: «На словах обещается реализация величайших ценностей, на деле же ... достигаются совершенно иные результаты. Революции скорее не социализируют людей, а биологизируют; не увеличивают, а сокращают все базовые свободы; не улучшают, а ухудшают экономическое и культурное положение рабочего класса. Карает же она ... не столько аристократические классы, сколько миллионы беднейших и трудящихся классов, которые в своем пароксизме надеются раз и навсегда революционным путем покончить со своей нищетой» [Там же]. Жертвами революционного взрыва могут оказаться как виновные, так и невиновные. Усталость, голод, нужда, пришедшие на смену выброшенной огромной энергии, делают людей вялыми и послушными. «Люди становятся все менее адаптивными к окружающей среде и взаимным отношениям. Их совокупную оценку можно выразить словами: «Дальше так жить невозможно, нужен порядок, порядок любой ценой»» и тогда «хвала «освободителям» от старого режима сменяется восхвалением «освободителей» от революции, иными 
словами - организаторов порядка» [Там же. С. 293]. Поэтому Сорокин утверждает, что революция с молчаливого согласия усталых измученных масс неизбежно порождает тиранию.

Французская революция XVIII века обосновывалась необходимостью грядущей справедливости, основанной на всеобее равенстве. Идея равенства стала служить оправданием и для большинства последующих революций. И. А. Ильин опровергал эту идею и утверждал, что равенство принципиально невозможно и что данная ложная установка приводит к революционным катастрофам, которые в конечном счете не приводят ни к какой справедливости. «Нельзя взыскивать со всех одинаково: есть малолетние и невменяемые, с них взыскивается меньше, есть призванные к власти, с них надо взыскивать строже и т. д. ... Справедливость не может требовать одинакового обхождения с неодинаковыми людьми; напротив, она требует неравенства для неравных, но такого неравенства, которое соответствовало бы действительному неравенству людей ... Она требует предметно-обоснованного неравенства ... В основе ее лежит внимание к человеческой индивидуальности и жизненным различиям» [10, с.317]. Детей важно беречь, героев чествовать, с одаренных - спрашивать по их способностям, честным доверять, к усталому - относиться снисходительно. Тем более нелепо выглядят, с точки зрения Ильина, попытки установить равенство путем революции, так как «она слепа, она разрушительна» и «дышит ненавистью и местью» [Там же. С. 318].

Революция, как утверждал Э. Гидденс, всегда предполагает насилие со стороны участников массового движения и является «наиболее драматичным и имеющим серьезные последствия примером нетрадиционного политического действия» [3, с. 386]. «Насильственным коллективным действием» назвал революцию и известный теоретик революции Чарльз Тилли [11].

«Революции, особенно успешные, - пишет П. Штомпка, - создают героические мифы; их достижения преувеличиваются, а потери игнорируются. Но потом эйфория проходит, становятся очевидными побочные негативные последствия, «эффекты бумеранга», человеческие жертвы» [9, с. 206]. Революция радикальна; и те, кто к ней призывает, верят в ее необходимость и неизбежно следуют этике жертв, когда «прогресс общества осуществляется, согласно неумолимым законам, ценою свободы и счастья индивидов и групп индивидов» [12, с. 174]. Карл Поппер, считавший революцию проявлением радикального холизма и следствием веры в существование законов исторической неизбежности, утверждал, что крупномасштабные эксперименты во имя ожидаемого светлого будущего предполагают сопротивление и, следовательно, подавление или даже истребление тех, кто таким экспериментам сопротивляется. Свою книгу «Нищета историцизма» он посвятил «памяти бесчисленных жертв... веры в неумолимые законы исторической неизбежности» [13, с. 49]. То есть речь идет о создании идеального общества для потомков ценой жизни живущих ныне.

В глобальном мире «на нашу жизнь оказывают влияние люди, которых мы никогда не видели и с которыми не знакомы, люди, которые, возможно, живут на другом конце земли от нас» [3, с. 585]. С развитием социальной рефлексивности, о которой говорит Э. Гидденс и которая отличает современное общество, революции становятся управляемыми и могут не назревать естественно в самом обществе, а быть искусственно организованными извне в целях дестабилизации [14]. Но эта же 
самая рефлексивность позволяет распознать это внешнее влияние и по возможности предотвратить его.

\section{Ссылки / References}

1. Спенсер Г. Социальная статика. Пер. с англ. Киев: Гама-Принт, 2013. 496 с.

2. Сорокин П. Социология революции // Сорокин П. Человек. Цивилизация. Общество / Общ. ред., сост. и предисл. А. Ю. Согомонов; пер. с англ. М.: Политиздат, 1992. С. 266-294.

3. Гидденс Э. Социология. Пер. с англ. Изд. 2-е. М.: Едиториал, УПСС, 2005. 632 с.

4. Лебон Г. Психология народов и масс. СПб.: Макет, 1995. 311 с.

5. Лебон Г. Психология толп // Психология толп. М.: Институт психологии РАН, КСП+, 1998. C. $13-254$.

6. Тард Г. Мнение и толпа // Психология толп. М.: Институт психологии РАН, КСП+, 1998. C. $255-412$.

7. Бауман 3. Ретротопия. М.: ВЦИОМ, 2019.160 с.

8. Поппер К. Р. Открытое общество и его враги. Том 1: Чары Платона / пер. с англ.; под ред. В. Н. Садовского. М.: Феникс, 1992. 448 с.

9. Штомпка П. Социология социальных изменений. М.: Директ-Медиа, 2007. 828 с. URL: http://biblioclub.ru/index.php?page=book\&id=26598 (дата обращения: 20.01.2020).

10. Ильин И. А. Поющее сердце // Ильин И. А. Соч. в 2 т. Т. 2. М.: Медиум, 1994. С. 305-374.

11. Тилли Ч. От мобилизации к революции / пер. с англ. Д. Карасева; под науч. ред. С. Моисеева. М.: Издательский дом НИУ ВШЭ, 2019. 432 с.

12. Швейцер А. Благоговение перед жизнью. М., 1992. 576 с.

13. Поппер К. Р. Нищета историцизма / пер. с англ. С. А. Кудриной // Вопросы философии. 1992. № 8. C. 49-79.

14. Что надо знать о «цветных революциях» / под общ. ред. А. Б. Ананченко. М.: Московский педагогический государственный университет, 2016. 135 с. URL:

http://biblioclub.ru/index.php?page=book\&id=469557 (дата обращения: 24.01.2020). 